\title{
Cultivating student understanding of context through drama and scriptwriting
}

\author{
Matthew Michaud Todd Hooper
}

\begin{abstract}
This paper presents an English as a foreign language (EFL) drama in language acquisition scriptwriting project that took place at a four-year private university located in Japan. The focus of this project was twofold: firstly, to see if students' cognition of situational context improved after completing scriptwriting exercises, and secondly to see if role-playing the scripts increased awareness in the identification of setting, roles of speakers, and purpose while increasing language aptitude. Furthermore, this study addresses the insufficient communicative competence abilities of Japanese students who have had years of structured English study. Their lack of communicative abilities may be attributed to the method of English instruction used in Japan such as focusing on grammar and vocabulary in isolated example sentences. This lack of context in second language (L2) instruction may leave students with limited communicative competence (Brown, Collins \& Duguid 1989; South, Gabbitas \& Merrill 2008). If students improve their understanding of the context of language use, they may become better equipped to use the language they know. One approach that may help students improve this understanding of context is scriptwriting and drama (Belliveau \& Kim 2013; Davies 1990). The results of this study indicate that participating in scriptwriting activities may improve students' ability to identify the context of conversations.
\end{abstract}

\section{Introduction}

English language study is a big part of education in Japan, and is a required element on most university entrance exams. Despite the large amount of time devoted to English study in the Japanese education system, many students' language proficiency is not sufficient for basic communication. One reason for this might be the way English is taught through grammar-translation exercises and isolated vocabulary activities (Michaud 2015: 232). While those activities and exercises give students a basic level of knowledge, the lack of context in the language they are studying tends to leave students with little understanding about its appropriate usage. In order to become better speakers 
of English, students need to have a deeper understanding of the context of language use. By learning about settings, roles of speakers, and relationships between them as well as communicative purposes, students may develop such an understanding. Two approaches that may lead to a better understanding of the context of language use are scriptwriting and role-play. Through these approaches, students must consider not only the words that characters say, but must also take into account the context of the conversations.

\section{The teaching context}

English is a required subject on university entrance exams in Japan. Therefore, the average Japanese university student has six years of English during secondary school, with an emphasis on grammar-translation. The lack of opportunity to use English to express their own ideas leaves students little ownership of the language (Donnery 2010). As a result of focusing on forms over context, students may find it difficult to acquire language skills and knowledge for the long term (Brown et al. 1989). According to South et al. (2008: 233), "research in second language acquisition over the past three decades has shown that focusing instruction on learning grammatical forms does not lead to fluency in real language use."

On the other hand, students with study abroad experience tend to be conversant in English. What these students experience is language in context. It is possible that, by focusing on the context of language use rather than the language itself, even students without overseas study might experience progress in using English as a communicative tool. Thus, how can educators provide opportunities for their students to focus on the context of the language they are using? One possible idea is drama. Drama in language acquisition offers the learner "a chance to educate, entertain and engage with a particular social issue while losing cognizance that this is being done through the target language of English" (Donnery 2010: 24).

\section{Drama in Education}

\subsection{Contextual and scripted drama}

The process of using scriptwriting to explore a variety of contexts and characters in role-play can be an excellent way to encourage L2 learners use creativity and imagination in a constructive environment where all students are working towards similar goals (Donnellan \& Simpson 2015; Stinson \& Winston 2011). Regarding the role-play activities in this study, and taking into account students' low-level skills in oral communication, it is also argued that scripted role-plays are important in the process of developing students' understanding of situational contexts. Burke (2013: 19) states that contextual drama has distinguishing factors that set it apart from theatre in that it uses role-play as a means to 
include participants by having them act as if they are someone else in any given situation that has a "particular focus and purpose." Contextual drama as defined by Burke is "a particular human condition or state of being. Therefore, it involves exploring and examining the circumstances of 'particular human conditions', specifically those which are 'life changing' to the people involved" (ibid. 19). For Bolton, contextual role-play is a "dramatic exercise form" that is characterized by several features. These features illustrate that contextual role-play "gives the participants practice in some social skill, concentrates on external behavior," and does not need much time to complete (Bolton 1979: 69). Furthermore, "the purpose should always be clear to the participants," the structure should be accurate, a sense of instantaneous achievement should be realized, and that the end of the role-play should try to be as clear as possible (ibid. 69).

In contextual drama in a foreign language classroom, both instructors and participants must equally have an understanding that as a group they are not necessarily creating a finalized project or play. Contextual drama allows L2 students to use their own knowledge, ideas, and wants to pursue the exploration of areas in their lives using drama. Additionally, in role-plays, students look at different aspects of real life through a different lens, are their own audience, and reflect on the effectiveness of their work after performing. The last factor is that contextual drama has no written script "thus requiring the players to find their own words (and/or actions) to work appropriately in the imaginary real-life situations with which they are engaged" (Burke 2013: 20). However, the absence of a script can cause anxiety in Japanese students. Japanese cultural norms advocate the avoidance of uncertainty (Hofstede, Hofstede \& Minkov, 2010). When given a task to participate in drama with no preparation, Japanese students may refuse to participate rather than risk making mistakes. In order to address this cultural issue, this research uses scripted role-plays called scripted drama, as they use elements that exist in contextual drama (drama set in a certain situation) yet adds a script. Students are finding their own words and actions, when they are given the opportunity to co-create their own dialogues.

\subsection{Voice and affective space}

The freedom that imaginary contexts afford L2 students is important: "participants are deliberately removed from the realistic here and now situation" (Kao \& O'Neill 1998: 82). This independence liberates students from their current location, the archetypal, teacher-centered, top-down transmission classroom that allows for very little creative growth (ibid.). Allowing students to decide what characters, settings, and stories to create enables them to explore their voices, or their identities in a foreign language, which can lead to the gradual adoption of the foreign language as a part of their identities (Pennycook 1997; Norton 1997). In exploring their voices, students can choose the language they would like to use and would like to learn, which gives them control of this aspect of their education (Macaro 2008). Drama allows students 
the ability to use other strengths, which others might not know about, such as their sense of humour or creativity, which gives them further opportunities to connect the language they are learning with their identities. More important is that the imaginary roles and invented contexts change the classroom climate allowing students to reflect after their performances, which may lead them to become more self-aware the next time they perform.

Affective spaces afford L2 students the freedom to express themselves while building interpersonal skills and relationships free from high levels of anxiety. "Drama activities [...] successfully break the fixed social rules of the formal school setting by inviting the participants to experiment with different roles under various imaginary conditions in a very safe manner" (Kao \& O'Neill 1998: 83). Affective spaces, paired with drama, can create an environment of trust and trigger heightened motivation and achievement within L2 students (Piazzoli 2011). These safe spaces in a student-centered classroom also contribute to increased motivation and autonomy (Dörnyei 2001). Students may choose to be humorous or to be serious. They can explore characters similar to themselves, or they can choose to become someone quite different. This freedom to find their voices in character can be a highly motivating factor (Kenny 1993). Furthermore, "trying things out in drama is pleasant and non-threatening for L2 learners because they face the tension of making decisions without the pressure and fear of making mistakes" (Kao \& O’Neill 1998:82).

Drama in the language classroom is ultimately indispensable because it offers a lens for learners to use their imagination. It draws upon students' abilities to imitate and express themselves and, if well handled, it should rouse interest and foster personality development. Drama encourages adaptability, fluency and communicative competence. It puts language into context. (Belliveau \& Kim 2013: 6)

\subsection{Personal development in the second language classroom}

Piazzoli (2014: 6) states in her own research on authenticity based on Heathcote's "notion of authenticity in teaching" that through drama, "'authentic' [language] activated cognitive, social and affective responses in the learners."

Scriptwriting and drama activities increase students' fluency, and also support the development of self-confidence in their ability to converse. Dorothy Heathcote and Gavin Bolton are at the forefront of drama education due to their "emphasis on the significance of drama in the learning process" and use of "drama for personal development" (Kao \& O'Neill 1998: ix). The EFL teacher who wishes to work with drama must be flexible and inventive, as this is "paramount in effective language teaching" (ibid. 1). Kao and O'Neill, in the research for their book, asked various language teachers why they supported drama approaches in teaching foreign languages. The teachers resoundingly stated that drama activities in the language classroom brought about a "different learning atmosphere' in their classrooms" (ibid. 80). Most of their interviewees seemed to agree that "the dynamic nature of drama activities creates a lively, 
enjoyable learning environment, motivates students to participate in classroom activities, and helps to build up the students' confidence in learning the target language" (ibid.).

\section{Research question}

In creating scripts, students have to focus on who is speaking, where the conversation is taking place, and why the participants are speaking. Giving students the opportunity to explore the characters and situations they are interested in can shift their attention from language form to the context of the language they are using. Also, by making drama contextual, students may focus on how language is used in the context of character, setting and purpose. Exploring these ideas is the aim of this research, and brings up the following research questions:

- Will participation in scriptwriting and role playing improve students' ability to identify the speakers, locations and purposes of conversations?

- Will students who have more opportunities to participate in scriptwriting and role playing show greater improvement in their ability to identify the speakers, locations and purposes of conversations?

\section{Method}

\subsection{Participants and procedures}

This study was conducted at a four-year private university located in Japan. The students who were enrolled in the course fulfilled the English language requirement. A total of 212 first-year students participated in the study. 103 participants $(n=103)$ took part in a light scriptwriting treatment that consisted of two 90-minute scriptwriting classes and two 90-minute script presentation classes. 109 participants $(n=109)$ took part in an intensive scriptwriting treatment that consisted of four 90-minute scriptwriting classes and four 90-minute script presentation classes.

A pre-test and a post-test consisting of four items each were administered to both groups before and after the respective interventions (see Appendix A and B). Each item consisted of a two-line exchange and four short-answer questions. Participants were asked to demonstrate their understanding of the context of the exchanges by identifying the setting, the purpose and the roles of the two speakers in each exchange. Answers were scored by the authors as correct if they were appropriate for the given exchange whether they were the answers predicted by the researchers or not. The percentage of correct answers on the pre-tests and post-tests for each group were compared to see if any difference in improvement could be observed between the two courses. 


\subsection{Treatment}

In both the light and heavy scriptwriting courses, emphasis was placed on students having the opportunity to write down their own conversations as well as the freedom to be creative. The main difference between the two treatments was the amount of time devoted to scriptwriting in the course. Instructors encouraged students to focus on the context of their scriptwriting efforts by having them (1) create their own characters, (2) create their own settings, and (3) choosing appropriate language for their scripts based on (1) and (2). Students worked in pairs on their scripts. This type of collaboration is said to aid in the construction of knowledge and in creating a positive attitude toward learning (Brown et. al. 1989; Kao \& O’Neill 1998). Instructors gave outlines of the steps that scripts usually take (create two characters and the setting, followed by writing dialogue and actions) but rather than giving explicit instructions on scriptwriting itself, instructors took on the role of facilitator. In other words, they monitored students' pair writings and provided supportive feedback.

Creating characters can help students develop an understanding of context by discussing the different viewpoints of characters and their different ways of reacting to situations. While students may have extensive knowledge on this in their first language, their lack of proficiency in English leaves them unprepared to use this knowledge in the target language. By explicitly focusing on differing character viewpoints, students are afforded the opportunity to reflect on the gaps in their language knowledge, which they can explore when they begin writing their scripts. As a part of the scriptwriting experience, students in both courses were asked to bring a variety of pictures printed from the Internet to class. They worked with their partners to describe their pictures using adjectives. This focused students on the wide variety of character types and how they may behave differently and how they may interact with each other. Once students finished this activity, they selected two pictures that they would like to use for the characters of their script. Then they selected a name and a profession for their characters, which provided clues about the possible context of the conversation. For example, if a character is a doctor, it may lead students to writing a conversation which takes place at a hospital, and a doctor may speak more formally when talking with a patient. In short, the richer and more descriptive the character creation process is, the easier it becomes for students to visualize the context of the script they would like to write.

The next step in the scriptwriting process in both courses was the creation of settings. In creating settings, students placed their characters in a location where they would be likely to interact. Students were encouraged to think about how locations can influence the way that characters would behave. For example, formal settings would call for more formal language while more casual settings would not.

Following example scripts, the student pairs finished creating their characters and settings; they began writing the dialogue and actions for their scripts. At this stage of scriptwriting, a strong emphasis was put on the appropriateness of 
language. Students were asked to think about factors that may influence the words and phrases that characters might use: the personalities, status, roles of their characters, and their relationships. As students worked on their scripts, the instructors monitored them closely and provided feedback to help students notice these points. Some examples of the kind of feedback here are:

- "What is this character's personality like? Does this line seem like something a shy person would say? How could you change it?"

- "This line seems very formal for two friends meeting at the station. Why did you choose to make this line formal?"

- "Both characters seem to be reacting in the same way. How can you make these characters different by changing their words?"

- "What is the purpose of this conversation? Perhaps this character would be more successful if he were more polite."

- "I can easily see this character is a doctor, because that's the way my doctor talks."

The goal of the instructors in giving this kind of feedback was to help students notice the way in which purpose, role, and setting can influence the language that L1 (first language) speakers use. This can help students become more aware of the context of the language they are studying and using in class. This kind of feedback may be interpreted as being directive, but it is important to keep in mind that the participants had a low level of English proficiency, so they were apt to make considerable errors in usage and grammar. Therefore, they required support in these areas. Low proficiency students tend to write simple sentences, which can be very direct and can be interpreted as rude. For example, "What do you want?" is probably not the best way to open a business meeting. Special care was taken to help students choose the language for what they intended to say that was appropriate to the context of their conversations. In other words, the researchers did not use feedback to change the conversations or the students' ideas, but to provide feedback on language usage.

This three-step process of scriptwriting (creating characters, creating settings, writing dialogues) was completed twice in the light scriptwriting treatment and four times in the intensive scriptwriting treatment. Students in both treatments were able to create meaningful and creative written output in English (see Appendix C).

One to two weeks after writing their scripts, students were required to perform them in front of the class. This gave students ample time to learn their lines, and practice their actions and gestures. This provided students with further opportunity to think about the relationship between the dialogue of their scripts and the context provided by the roles, the settings, and the purposes of their conversations. Presentations took place two times in the light scriptwriting treatment and four times in the intensive scriptwriting treatment. 


\section{Results}

Results show that both groups, after undergoing the scriptwriting treatment, showed improvement in their ability to identify the settings, the roles of speakers, and the purposes of short exchanges. Additionally, the participants subjected to the intensive scriptwriting treatment (Table 1) showed greater improvement in their ability to identify these three factors than the participants who underwent the light scriptwriting treatment (Table 2). Those who underwent the intensive treatment improved their scores 2.1 percentage points more than the light treatment group when identifying settings, 2.1 percentage points more when identifying the roles of speakers, and 2.5 percentage points more when identifying the purposes of short exchanges. An important point to note is that the average scores in identifying these three factors of context improved in both treatment groups (Table 3), which leads to the conclusion that even limited scriptwriting experience can improve students' awareness of conversational context.

\section{Discussion}

Scriptwriting is one way to improve students' awareness of context, and this study aimed to show that this awareness might help students focus on thinking about how to use the language they learn. In both of the treatments in this study, students had to make decisions on their own about what kind of scripts to create. The scripts could be serious or they could be comical. They could depict common situations or unusual ones. Students could create characters that resembled themselves, or they could explore new roles.

Scriptwriting allows students to engage with aspects of their identities and develop new personas through which they can experiment with and manipulate the language that they have learned. In other words, they can find their voice in a foreign language. Through this experimentation and self-discovery students gain control over the choice of the language they use and learn. This control can become a first step towards becoming a self-directed learner in the future.

Another possible benefit of scriptwriting is that students work at the level they are comfortable with. Students with low confidence can work with language that they already know - which may improve their confidence - while students who are comfortable pushing themselves can attempt to use more challenging vocabulary, expressions, or grammar. Such differentiated classrooms allow mixed-level groups to work together on the same project. This may be particularly beneficial when teaching students from a culture with a high level of risk avoidance, such as in Japan (Hofstede, Hofstede \& Minkov 2010). In countries with a high level of risk avoidance, students may avoid participating in classroom activities if they feel that the chances of making mistakes are high, or if they evaluate activities as too difficult. With mixed-level groups working of scriptwriting, the pressure to not make mistakes is reduced since students are working at a level that is appropriate for them. Additionally, this ability to 


\begin{tabular}{|c|c|c|}
\hline \multicolumn{3}{|c|}{ Table 1. Intensive Scriptwriting Treatment Group Test Scores } \\
$n=109$
\end{tabular}

\begin{tabular}{|c|c|c|}
\hline \multicolumn{3}{|c|}{ Table 2. Light Scriptwriting Treatment Group Test Scores } \\
$n=103$
\end{tabular}

\begin{tabular}{|c|c|c|}
\hline \multicolumn{3}{|c|}{ Table 3. Increase in Average Scores in Percentage Points } \\
\hline & $\begin{array}{c}\text { Intensive Scriptwriting } \\
\text { Treatment Group } \\
(n=109)\end{array}$ & $\begin{array}{c}\text { Light Scriptwriting } \\
\text { Treatment Group } \\
(n=103)\end{array}$ \\
\hline Identifying the Setting & 13.8 & 11.7 \\
\hline Identifying the Roles of Speakers & 13.4 & 11.3 \\
\hline Identifying the Purpose & 8.1 & 5.6 \\
\hline
\end{tabular}

work at their level when creating scripts encourages students to use their prior knowledge of language and context. This means that students will be able to construct knowledge from their current level, which would probably not be the case if students were working with fixed conversations provided by a teacher.

\section{Limitations of the research}

One of the limitations of this study is that due to teaching circumstances, no comparison of scriptwriting with other activities took place. Since it was not possible to conduct a control group, it cannot be claimed that scriptwriting is more effective at improving students' identification of context than other methods. Additionally, the courses that students participated in during the treatment were four-skill courses (listening, speaking, reading, and writing), which limited the amount of scriptwriting that could be done per semester, as 
class time needed to be devoted to other skills covered in the courses. The short treatment period may also have limited the effectiveness of the treatment.

Another limitation that became apparent was the design of the pre- and post-test. There were items in which student experience may have influenced their understanding of context. For example, the question item regarding the hot water not working in the room (see Appendix A, question 3), was designed as a short exchange between a hotel guest and a hotel clerk, and there were many students who interpreted this as happening in a hospital between a patient and a doctor. As first year university students, they may have experiences of staying at hotels, but many of these students may have only travelled with their families, so if there was a problem with the water in their hotel room, then perhaps their parents would have handled it, and therefore the students themselves may have never experienced this situation themselves. This calls for an investigation into the relationship between the understanding of context and experience.

Culture may also have played a role in the interpretation of context. For example, the "Give me a chance" conversation, which was designed as a conversation between a player and a coach (see Appendix B, question 2), may have been difficult for some students to interpret due to their cultural perspective. While answers other than "player" and "coach" were accepted as correct if they fit the conversation, many students were not able to give a contextually appropriate answer. In Western cultures, it would not be unusual for a player to make a direct request to a coach like this. However, a Japanese player might not make such a direct request to a person of authority (Hofstede, Hofstede \& Minkov 2010). It is possible that differing cultural expectations caused interference in the test. A study of the role of culture in context identification may provide insights that would be beneficial for language teachers.

\section{Conclusion}

With a stronger ability to identify the context of conversations through scriptwriting and the performance on those scripts, students may come to understand how the grammar and vocabulary they already know can be used in practical and realistic ways. It is also possible that such understanding may make the relevance of English study clearer. Also, the autonomy which students experience with scriptwriting stands in stark contrast to their English education experiences in secondary schools in Japan.

Another strength of scriptwriting with a partner is that it puts the focus on students rather than on the teacher. This allows students to take more control not only of the content of their scripts, but also the scriptwriting process. This responsibility encouraged students to be more proactive. While this study shows that students improved their ability to identify the context of conversations, it does not make a connection between this ability and the communicative ability of the students. This would be an area that would benefit from future research. 


\section{Bibliography}

Belliveau, George \& Kim, Won (2013): Drama in L2 learning: A research synthesis. In: Scenario 2, 6-26

Bolton, Gavin (1979): Towards a theory of drama in education. London: Longman Group UK Limited

Brown, John Seely; Collins, Allan \& Duguid, Paul (1989): Situated cognition and the culture of learning. In: Educational Researcher 18/1, 32-42

Burke, Margaret R (2013): Gavin Bolton's contextual drama: The road less traveled. Chicago: University of Chicago Press

Davies, Paul (1990): The use of drama in English language teaching. In: TESL Canada Journal 8/1, 87-99

Donnellan, Mark \& Simpson, David (2015): Acting for EFL students: Script analysis and rehearsal techniques. In: Annual Research Report of the Language Center, Kwansei Gakuin University 18, 63-82

Donnery, Eucharia (2010): Deconstructing the bully and victim dichotomy. In: Scenario 2, 22-35

Dörnyei, Zoltan (2001): Motivational strategies in the language classroom. Cambridge: Cambridge University Press

Hofstede, Geert; Hofstede, Geert Jan \& Minkov, Michael (2010). Cultures and Orginizations: Software of the Mind. New York: McGraw-Hill Education

Kao, Shin-Mei \& O'Neill, Cecily (1998): Words into worlds: Learning a second language through process drama. Standford \& London: Ablex Publishing Corporation

Kenny, Brian (1993): For more autonomy. In: System 21/4, 431-442

Macaro, Ernesto (2008): The shifting dimensions of language learner autonomy. In: Lamb, Terry \& Reinders, Hayo (eds.): Learner and Teacher Autonomy: Concepts, Realities and Responses. Amsterdam: John Benjamins, 43-62

Michaud, Matthew (2015): Oral communication in the Japanese senior high school: Communicative competence and comparisons of textbooks used for EFL instruction. In: Journal of Linguistics and Language Teaching 6/2, 231-257

Norton, Bonny (1997): Language, identity and the ownership of English. In: TESOL Quarterly 31/3, 133-158

Pennycook, Alastair (1997): Cultural alternatives and autonomy. In: Benson, Phil \& Voller, Peter (eds.): Autonomy and Independence in Language Learning. London: Longman, 35-53

Piazzoli, Erika (2014): The 'authentic teacher': Heathcote's notion of 'authenticity' in second language teaching and learning. Drama Research: International Journal of Drama in Education, 5/1, 2-19 
Piazzoli, Erika (2011): Process drama: The use of affective space to reduce language anxiety in the additional language learning classroom. In: RiDE: The Journal of Applied Theatre and Performance 16/4, 557-573

South, Joseph, B; Gabbitas, Bruce \& Merrill, Paul F. (2008): Designing video narratives to contextualize content for ESL learners: A design process case study. In: Interactive Learning Environments 16/3, 231-243

Stinson, Madonna \& Winston, Joe (2011): Drama education and second language learning: A growing field of practice and research. In: RiDE: The Journal of Applied Theatre and Performance 16/4, 479-488 


\section{Appendix A: Pre-test questionnaire}

\begin{tabular}{|c|c|c|c|}
\hline \multicolumn{4}{|c|}{$\begin{array}{l}\text { Context Comprehension Questionnaire } \\
\text { This is a test to demonstrate how well you can guess the content after reading short } \\
\text { conversations. Please read each conversation and answer the following questions. Answers do } \\
\text { not have to be in English. }\end{array}$} \\
\hline \multicolumn{2}{|c|}{$\begin{array}{l}\text { Q1: } \\
\text { A: This milk tastes bad. } \\
\text { B: I'm very sorry about that. l'll get you } \\
\text { a new glass right away. }\end{array}$} & \multicolumn{2}{|c|}{$\begin{array}{l}\text { Q2: } \\
\text { A: Give me a chance. I'm ready! } \\
\text { B: I'm not sure if you are ready to play } \\
\text { yet. }\end{array}$} \\
\hline \multicolumn{2}{|l|}{$\begin{array}{l}\text { Where does the } \\
\text { conversation take place? }\end{array}$} & \multicolumn{2}{|l|}{$\begin{array}{l}\text { Where does the } \\
\text { conversation take place? }\end{array}$} \\
\hline \multicolumn{2}{|l|}{ Who is speaker A? } & \multicolumn{2}{|l|}{ Who is speaker $A$ ? } \\
\hline \multicolumn{2}{|l|}{ Who is speaker $B$ ? } & \multicolumn{2}{|l|}{ Who is speaker $B$ ? } \\
\hline \multicolumn{2}{|l|}{$\begin{array}{l}\text { What is the purpose of } \\
\text { this conversation? }\end{array}$} & \multicolumn{2}{|l|}{$\begin{array}{l}\text { What is the purpose of } \\
\text { this conversation? }\end{array}$} \\
\hline \multicolumn{2}{|c|}{$\begin{array}{l}\text { Q3: } \\
\text { A: These shoes are on sale until } \\
\text { Monday. } \\
\text { B: They are not really what I am } \\
\text { looking for. }\end{array}$} & \multicolumn{2}{|c|}{$\begin{array}{l}\text { Q4: } \\
\text { A: Why didn't you come home last } \\
\text { night? } \\
\text { B: I was having fun with my friends. }\end{array}$} \\
\hline \multicolumn{2}{|l|}{$\begin{array}{l}\text { Where does the } \\
\text { conversation take place? }\end{array}$} & $\begin{array}{l}\text { Where does the } \\
\text { conversation take place? }\end{array}$ & \\
\hline \multicolumn{2}{|l|}{ Who is speaker A? } & Who is speaker $A$ ? & \\
\hline \multicolumn{2}{|l|}{ Who is speaker $B$ ? } & Who is speaker B? & \\
\hline $\begin{array}{l}\text { What is the purpose of } \\
\text { this conversation? }\end{array}$ & & $\begin{array}{l}\text { What is the purpose of } \\
\text { this conversation? }\end{array}$ & \\
\hline
\end{tabular}




\section{Appendix B: Post-test questionnaire}

\section{Context Comprehension Questionnaire}

This is a test to demonstrate how well you can guess the content after reading short conversations. Please read each conversation and answer the following questions. Answers do not have to be in English.

Q1:

A: I had an accident and I hurt my leg.

B: OK. Please fill out this form.

\begin{tabular}{|l|l|}
\hline $\begin{array}{l}\text { Where does the } \\
\text { conversation take place? }\end{array}$ & \\
\hline Who is speaker $A$ ? & \\
\hline Who is speaker B? & \\
\hline $\begin{array}{l}\text { What is the purpose of } \\
\text { this conversation? }\end{array}$ & \\
\hline
\end{tabular}

Q3:

A: The hot water doesn't work in my room.

B: Would you like to change rooms?

\begin{tabular}{|l|l|}
\hline $\begin{array}{l}\text { Where does the } \\
\text { conversation take place? }\end{array}$ & \\
\hline Who is speaker A? & \\
\hline Who is speaker B? & \\
\hline $\begin{array}{l}\text { What is the purpose of } \\
\text { this conversation? }\end{array}$ & \\
\hline
\end{tabular}

Q2:

A: What do you recommend for a sore throat?

B: Why don't you try this one?

\begin{tabular}{l|l|}
$\begin{array}{l}\text { Where does the } \\
\text { conversation take place? }\end{array}$ & \\
\hline Who is speaker $A$ ? & \\
\hline Who is speaker $B$ ? & \\
\hline $\begin{array}{l}\text { What is the purpose of } \\
\text { this conversation? }\end{array}$ & \\
\hline
\end{tabular}

Q4:

A: You need to bend your legs like this.

B: Like this?

\begin{tabular}{|l|l|}
$\begin{array}{l}\text { Where does the } \\
\text { conversation take place? }\end{array}$ & \\
\hline Who is speaker A? & \\
\hline Who is speaker B? & \\
\hline $\begin{array}{l}\text { What is the purpose of } \\
\text { this conversation? }\end{array}$ & \\
\hline
\end{tabular}




\section{Appendix C: Example role-play}

FADE IN:INT: KOSHIEN STADIUM, A CLEAR SKY, A FINE DAY - JULY 3TOM is a rugby player. He is famous for being a strong player. He is 180 centimeters tall; his face is very small and cool. JESSIE is a manager of TOM's rugby team. She is always full of energy. Now, they will have a very important game.TOM:I'll do my best today!JESSIE:Tom, today, the director of the national Japanese rugby team, Eddie Jones will come!TOM:(Surprised)What!?JESSIE:He comes to see INAMURA, the player of today's opposing team.TOM:Well. . . if I defeat him, I'll be a star. I'll show off my abilities!TOM is delighted and raises his fists in victory.JESSIE:Tom, do your best. You can do it!TOM:(The game starts, kick off)OK! Thank you.JESSIE clenches her hands and prays for Tom's success. INAMURA kicks the ball. TOM catches the ball while jumping. INAMURA makes a nice tackle on TOM. TOM steps and he quickly dodges INAMURA. INAMURA does it again. Finally, TOM tumbles down.JESSIE:(She opens her eyes with surprise.)Oh no...! JESSIE holds her mouth with both hands. (TOM cries in pain)JESSIE rushes over to TOM.What's wrong!?TOM:My knee... my knee...JESSIE:What happened?TOM:It's because of the tackle from INAMURA. . . I have a very sore knee. .. (He cries out.)JESSIE:He's such a fool... JESSIE tapes up and puts ice on TOM's knee. 